\title{
Human Embryonic Stem Cells in the Treatment of Patients with Traumatic Brain Injury
}

\author{
Geeta Shroff *
}

Founder and Medical Director, Nutech Mediworld, New Delhi-110016, India

Received: August 24, 2015; Accepted: October 15, 2015; Published: November 11, 2015

*Corresponding author: Dr. Geeta Shroff, Nutech Mediworld, H-8, Green park extension, New Delhi-110016, India, Phone: +91 1126180039 ; Fax: +91 11 26560089; Email: geetashroff@hotmail.com

\begin{abstract}
Introduction: Traumatic brain injury (TBI) usually results from a blunt or penetrating force to the head. Common manifestations include confusion, seizure, coma, focal sensory, altered level of consciousness, etc. Stem cell-based therapy is emerging as a promising therapeutic option for the treatment of TBI.
\end{abstract}

Materials and Methods: In the present study, two patients with TBI were treated with human embryonic stem cell (hESC) therapy.

Results: Following the treatment, both the patients showed remarkable changes and improvement in their clinical condition. No adverse event was reported during the course of therapy.

Conclusion: Despite the positive results, this investigation needs further research in order to understand the clinical utility of hESC therapy.

Keywords: Human embryonic stem cells; traumatic brain injury; stem cell therapy

\section{Introduction}

Traumatic brain injury (TBI) is defined as an alteration in the brain functions. Manifestation of TBI includes confusion, seizure, coma, focal sensory, altered level of consciousness; a motor neurologic deficit, which results from a blunt or penetrating force to the head [1].

In the United States, it is estimated to affect 138 people per day and about 52,000 people die annually due to TBI. Approximately, half of all TBI cases are caused by motor vehicle accidents [2, 3]. TBI is a major health problem [1] which directly and indirectly affects the quality of life (QoL) [4-6]. It is the most common cause of death and is placed third in total mortality rate after cancer and cardiovascular diseases [2].

Several treatment options such as surgery [7], physiotherapy [8] and biological $[9,10]$ are available for the treatment of TBI, but have their own challenges. Now-a-days, stem cell therapy is being explored for the treatment of TBI [11-13] given to the pluripotent nature and high potential of regeneration of these cells. Here, we report the safety and efficacy of human embryonic stem cell (hESC) therapy in two patients with TBI.

In our previous studies, we have shown the improvement in the condition of patients suffering from spinal cord injury (SCI), cerebral palsy (CP), cortical visual impairment, spinocerebellar ataxia and Friedreich's ataxia after hESC therapy [14-18].

\section{Materials and Methods}

The cells used in this study were cultured and maintained as per our proprietary in-house technology (Patent-WO 2007/141657A PCT/1B 2007 Published 13 Dec 2007), which is a Good Manufacturing Practice (GMP), Good Laboratory Practice (GLP) and Good Tissue Practice (GTP) certified laboratory. Establishment and characterization of the cell line is elaborated elsewhere [19]. The details of the techniques used to culture and differentiate hESCs are described in the patent [14]. The safety of hESCs has also been established in the treatment of various terminal conditions [20]. Both the patients provided written informed consent before the treatment. The study was approved by an Independent Institutional Ethics committee (IEC) that reports to the National Apex Committee for Stem Cell Research and Therapy (NAC-SCRT). The evidence for the use of hESCs at Nutech Mediworld has also been submitted in written and accepted by the House of Lords, Regenerative Medicine, Science and Technology Committee [21].

The study consisted of different treatment phases separated by the gap phases. The patients were first tested for hypersensitivity reactions with hESC ( $0.05 \mathrm{ml} \mathrm{hESC}$ injected subcutaneously).

Following safety evaluations, in first treatment phase (T1), $0.25 \mathrm{ml}$ hESCs ( $<4$ million cells) were administered through intramuscular (IM) route twice daily, $1 \mathrm{ml} \mathrm{hESCs}(<16$ million cells) were administered every 7 days through intravenous (IV) route and 1 to $5 \mathrm{ml}$ hESCs were administered every 7 days by any of the supplemental routes; such as intrathecal, caudal, brachial plexus block, epidural, deep spinal muscle etc. The patients were also given nasal sprays.

After a gap period of 4-8 months, the patients entered the subsequent treatment phases T2 (4 to 6 weeks) and T3 (4 to 6 weeks) where they were administered the same dosage regime as T1.

Duration of gap phase between different treatment periods was decided by keeping in mind the time taken for organogenesis 
in human fetus which takes $14-16$ weeks to develop a complete organ.

\section{Case Presentation}

\section{Case 1}

A 27-yr old male patient was admitted with complaints of loss of all motor functions of lower limbs (LL), restricted movement of both upper limbs (UL), no trunk control, atrophy of LL muscles and was wheelchair dependent. The patient had no bladder and bowel movement at the time of admission. The patient also had slurry speech and impaired cognitive function.

The patient history revealed that he had met with an accident in 2004. After the accident, he was admitted in one of the hospitals in Colombo, where he received preliminary treatment. The patient was paralyzed completely with no eye movement and also had ear, nose and throat (ENT) bleed. Gradually, over 2 weeks the patient started opening his eye. The patient shifted to Thailand, where he underwent right sided cranioplasty, with sided partial resection.

On examination, the patient had normal chest, cyclic vomiting syndrome (CVS), vitals were stable, had subconscious mental state, disoriented to time and place, had unclear speech, wheelchair dependent and claw deformity of right hand. Single photon emission tomography (SPECT) scan showed global cortical hypoperfusion with relative sparing of left parietal, left temporal and left occipital cortices.

At our facility, the patient was treated with hESCs as a primary therapy. After receiving two sessions of hESC theray for 8 weeks and 4 weeks, respectively, the patient showed significant improvement. Currently, the patient's mental state is normal. He is conscious, oriented, speech is near normal, is able to move his elbow and has normal trunk control. UL and LL have improved to $3 / 5$ and $1+/ 5$, respectively. SPECT scan following the therapy showed filling up of the area of lobectomy. There was significant decrease in the degree of hypoperfusion in cereberal and cerebellar regions.

\section{Case 2}

A 7-mon old baby girl was admitted with chief complaints of seizures, delayed milestones, no smile, poor control over head, neck and trunk and was not able to recognize her parents. Patient's history revealed that she was apparently healthy till 2-mon of age, but she was hit by a speeding vehicle and got a head injury. She was unconscious and was admitted at pediatric intensive care unit (PICU) for 2 weeks. There she was on ventilator support for 10 days. After getting discharged, the patient was noted to have increased head size and she underwent shunt surgery for hydrocephalus on 26 February, 2013.

Patient's birth history showed that she was born to a hypothyroid mother at full term via vaginal delivery and had spontaneous birth cry and birth weight was 7.8 pounds. The patient had TBI at the time of birth and had lactation by pump till 6 months.

On examination, the patient had an absence of eye contact, irritable, no primitive reflexes present, right eye not reacting to light and had stiffness in left ankle. SPECT scan before therapy showed severe hypoperfusion globally with relative sparing of the cerebellum.

At our facility, the patient underwent hESC therapy as a primary treatment along with occupational therapy. The patient received four sessions (first session for 8 weeks and the subsequent sessions of 4 weeks) of hESC therapy over the span of 1 yr. Following the treatment with the hESC therapy, an improvement was observed in primitive reflexes, LL tightness normalized and had better head, neck and trunk control. The patient was able to make sounds to convey her message, sleep well, started turning her body, and had an occasional involuntary smile. She was able to feed, initiated spoon feeding and stopped crying when comforted by her mother. She was able to focus and track objects. Following the therapy, SPECT scan showed improved hypoperfusion in cerebral and cerebellum regions.

\section{Discussion}

We used in-house cultured hESC in the treatment of two patients with TBI. The cell line has been derived from a single fertilized ovum 24-48 hr after fertilization, the cells are harvested when they have reached 4-16 cell stage. Media used in culturing the cell lines are free from animal contaminants and cells of animal origin [19]. After undergoing hESC therapy, patients showed signs of improvement in their health such as improvement in head, neck and trunk control, better bladder, and bowel movement, able to make sound to convey messages, movement in both UL and LL and eye movement. During the course of therapy, no steroids or immunosuppressants were given to the patients. These results showed that hESC therapy was effective in the treatment of both the patients. We used SPECT scan imaging to detect reduction in hypoperfusion. SPECT scan revealed moderate reduction in hypoperfusion in both the patients. In one of the patients, filling of the area of lobectomy was also noted.

During our study, we included a gap phase of 4-6 months between each treatment phase, so that hESCs can grow, repair and regenerate the affected area. The duration of gap phase was determined keeping in view the time taken for development of complete organs (14-16 weeks) in the human fetus [22]. The process of organogenesis in the human fetus takes an average time of 12 weeks. Similarly, stem cells take time to regenerate and repair the damaged tissue.

When stem cells are transplanted into the body, they migrate to the injured site and help in the recovery or regeneration of the injured tissue. Further, these cells start growing in the affected area to replace the degenerated cell type [23]. The regenerative potential of hESC allows for the damaged part of the brain to be repaired. Stem cells have the potential to communicate with the other cells of the body from the area of damage and "home" at the site of injury. Various factors such as chemokines, cytokines and growth factors released from the site of injury communicate with the transplanted stem cells. Selectins and integrins are present on the surface of stem cells, which are responsible to upgrade the whole mechanism [23-25]. 
Cell based therapy including mesenchymal stem cells (MSCs), induced pluropotent stem cells (iPSCs), endothelial progenitor cells (EPCs) and hESCs have tremendous potential for modelling neurological disorder [26-29]. We have already reported the efficacy and safety of hESC in a study involving 91 patients with CP. Improvement in patient's symptoms was assessed with the Gross Motor Function Classification System Expanded and Revised (GMFCS - E \& R) scale, an internationally accepted tool [14]. Further, Tajiri et al reported that stem cells served a biobridge in injured brain site to initiate the endogenous repair mechanisms [30]. The use of adult MSCs or stromal cells represent a promising new therapeutic approach as these cells have protective effects through the release of promitotic, antiapoptotic, antiinflammatory and immunomodulatory soluble factors [31]. Although physiotherapy plays an important role in TBI, but is unable to cure coma patients and prognostic potential for this therapy is still insufficient. Surgical treatment is another option to treat TBI, but is limited to treat mild TBI [32]. Mild hypothermia is also used for the treatment of brain and SCI, but this therapy has numerous pitfalls such as pathological and physiological changes as well as potential side effects are observed during this treatment [33].

\section{Conclusion}

Despite the positive results reported above, this investigation needs further research in order to understand the clinical utility of hESC therapy.

\section{Acknowledgements}

The author acknowledges all the doctors, staff and patients of the Nutech Mediworld. The author also acknowledges Knowledge Isotopes Pvt. Ltd. (http://www.knowledgeisotopes.com) for the writing support.

\section{References}

1. Bruns J Jr, Hauser WA. The epidemiology of traumatic brain injury: a review. Epilepsia. 2003; 44 Suppl 10: 2-10.

2. Franckeviciute E, Krisciunas A. Peculiarities of physical therapy for patients after traumatic brain injury. Medicina (Kaunas). 2005; 41(1): $1-6$.

3. Traumatic Brain Injury in the United States: Fact Sheet. Centers for Disease Control and Prevention. [cited 2014 Jul 22]; Available from: http://www.cdc.gov/traumaticbraininjury/get_the_facts.html.

4. Di Battista A, Soo C, Catroppa C, Anderson V. Quality of life in children and adolescents post-TBI: a systematic review and meta-analysis. J Neurotrauma. 2012; 29(9): 1717-1727.

5. Di Battista A, Godfrey C, Soo C, Catroppa C, Anderson V. Depression and health related quality of life in adolescent survivors of a traumatic brain injury: a pilot study. PLoS One. 2014; 9(7): e101842. doi: 10.1371/journal.pone.0101842.

6. Dijkers MP. Quality of life after traumatic brain injury: a review of research approaches and findings. Arch Phys Med Rehabil. 2004;85(4 Suppl 2):S21-35.

7. 7. Hartings JA, Vidgeon S, Strong AJ, Zacko C, Vagal A, Andaluz N, et al. Surgical management of traumatic brain injury: a comparative- effectiveness study of 2 centers. J Neurosurg. 2014; 120(2): 434-446. doi: 10.3171/2013.9.JNS13581.

8. S, Johannes S. Physiotherapy after traumatic brain injury: a systematic review of the literature. Brain Inj. 2008; 22(5): 365-373. doi: 10.1080/02699050801998250.

9. Nowrangi DS, Tang J, Zhang JH. Argon gas: a potential neuroprotectant and promising medical therapy. Med Gas Res. 2014; 4(1): 3. doi: 10.1186/2045-9912-4-3.

10. Esposito E, Cordaro M, Cuzzocrea S. Roles of fatty acid ethanolamides (FAE) in traumatic and ischemic brain injury. Pharmacol Res. 2014. 86: 26-31.doi: 10.1016/j.phrs.2014.05.009.

11. Tajiri N, Duncan K, Antoine A, Pabon M, Acosta SA, de la Pena I, et al. Stem cell-paved biobridge facilitates neural repair in traumatic brain injury. Front Syst Neurosci. 2014; 8: 116. doi: 10.3389/ fnsys.2014.00116.

12. Batista CE, Mariano ED, Marie SK, Teixeira MJ, Morgalla M, Tatagiba $M$, et al. Stem cells in neurology--current perspectives. Arq Neuropsiquiatr. 2014; 72(6): 457-465.

13. Xu HS, Ma C, Cao L, Wang JJ, Fan XX. Study of co-transplantation of SPIO labeled bone marrow stromal stem cells and Schwann cells for treating traumatic brain injury in rats and in vivo tracing of magnetically labeled cells by MRI. Eur Rev Med Pharmacol Sci. 2014; 18(4): 520-525.

14. World Intellectual Property Organization. Compositions comprising human embryonic stem cells and their derivatives, methods of use, and methods of preparation. [cited 2014 Jul 22]; Available from: https:// patentscope.wipo.int/search/en/detail.jsf?docId=W02007141657.

15. Shroff G, Das L. Human embryonic stem cell therapy in cerebral palsy children with cortical visual impairment: a case series of 40 patients. J Cell Sci Ther. 2014; 5: 189. doi: 10.4172/2157-7013.1000189.

16. Shroff G, Gupta R. Human embryonic stem cells in the treatment of patients with spinal cord injury. Ann Neurosci. 2015; 22(4). 208-216.

17. Shroff G. Human embryonic stem cells in the treatment of spinocerebellar ataxia: a case series. J Clin Case Rep. 2015; 4: 474. doi:10.4172/2165-7920.1000474.

18. Shroff G. A novel approach of human embryonic stem cells therapy in treatment of Friedreich's ataxia. Int J Case Rep Images. 2015; 6(5): 261-266. doi:10.5348/ijcri-201503-CS-10054.

19. Shroff G. Establishment and characterization of a neuronal cell line derived from a 2-cell stage human embryo: clinically tested cell-based therapy for neurological disorders. Int J Recent Sci Res. 2015; 6(4): 3730-3738.

20. Shroff G, Bharthakur JK. Safety of human embryonic stem cells in patients with terminal/incurable conditions. Ann Neurosci. 2015; 22(3). 132-138. doi: 10.5214/ans.0972.7531.220303.

21. House of Lords SATSC. [cited 2014 Sep 1]; Available from: http:// www.parliament.uk/documents/lords-committees/sciencetechnology/RegenerativeMedicine/RegenMed.pdf.

22. MedlinePlus. Fetal development.Available from: http://www.nlm.nih. gov/medlineplus/ency/article/002398.htm.

23. Eggenhofer E, Luk F, Dahlke MH, Hoogduijn MJ. The life and fate of mesenchymal stem cells. Front Immunol. 2014; 5: 148. doi: 10.3389/ fimmu.2014.00148.

24. Kang SK, Shin IS, Ko MS, Jo JY, Ra JC. Journey of mesenchymal stem cells for homing: strategies to enhance efficacy and safety 
of stem cell therapy. Stem Cells Int. 2012; Article ID: 342968. doi: $10.1155 / 2012 / 342968$.

25. Gnecchi M, Zhang Z, Ni A, Dzau VJ. Paracrine mechanisms in adult stem cell signaling and therapy. Circ Res. 2008; 103(11): 1204-1219. doi: 10.1161/CIRCRESAHA.108.176826.

26. Gupta K, Patani R, Baxter P, Serio A, Story D, Tsujita T, et al. Human embryonic stem cell derived astrocytes mediate non-cell-autonomous neuroprotection through endogenous and drug-induced mechanisms. Cell Death Differ. 2012; 19(5): 779-787. doi: 10.1038/cdd.2011.154.

27. Gupta K, Chandran S, Hardingham GE. Human stem cell-derived astrocytes and their application to studying Nrf2-mediated neuroprotective pathways and therapeutics in neurodegeneration. $\mathrm{Br}$ J Clin Pharmacol. 2013; 75(4): 907-918. doi: 10.1111/bcp.12022.

28. Donega V, Nijboer CH, van Tilborg G, Dijkhuizen RM, Kavelaars A Heijnen CJ. Intranasally administered mesenchymal stem cells promote a regenerative niche for repair of neonatal ischemic brain injury. Exp Neurol. 2014; 261: 53-64. doi: 10.1016/j.expneurol.2014.06.009.

29. Park KJ, Park E, Liu E, Baker AJ. Bone marrow-derived endothelial progenitor cells protect postischemic axons after traumatic brain injury. J Cereb Blood Flow Metab. 2014; 34(2): 357-366. doi: 10.1038/ jcbfm.2013.216.

30. Tajiri N, Kaneko Y, Shinozuka K, Ishikawa H, Yankee E, McGrogan M, et al. Stem cell recruitment of newly formed host cells via a successful seduction? Filling the gap between neurogenic niche and injured brain site. PLoS One. 2013; 8(9): e74857. doi: 10.1371/journal. pone.0074857.

31. Monsel A, Zhu YG, Gennai S, Hao Q, Liu J, Lee JW. Cell-based therapy for acute organ injury: preclinical evidence and ongoing clinical trials using mesenchymal stem cells. Anesthesiology. 2014; 121(5): 10991121.doi: $10.1097 /$ ALN.0000000000000446.

32. Overton TL, Shafi S, Cravens GF, Gandhi RR. Can trauma surgeons manage mild traumatic brain injuries? Am J Surg. 2014. 208(5): 806810. doi: 10.1016/j.amjsurg.2014.02.012.

33. Darwazeh R, Yan Y. Mild hypothermia as a treatment for central nervous system injuries: Positive or negative effects. Neural Regen Res. 2013; 8(28): 2677-2686. doi: 10.3969/j.issn.1673-5374.2013.28.010. 